\title{
Epoprostenol sodium (prostacyclin) infusion in acute myocardial infarction
}

\author{
FRANCIS J KIERNAN, JEFFREY KLUGER, JANE C REGNIER, \\ MARK RUTKOWSKI, ARNOLD FIELDMAN \\ From the Department of Medicine, Division of Cardiology, Hartford Hospital, Hartford, and the University of \\ Connecticut Health Center, Farmington, Connecticut, USA
}

SUMMARY Epoprostenol (prostacyclin) is a potent inhibitor of platelet aggregation and causes relaxation of vascular smooth muscle. These effects may be beneficial in patients with acute myocardial infarction. The effect of epoprostenol infusion in patients with acute myocardial infarction was evaluated in a randomised double blind study of 45 patients with evidence of myocardial infarction of $<16$ hours' duration. The patients were given a 72 hour infusion of epoprostenol (23) or placebo (22). The maximum dose was $5 \mathrm{ng} / \mathrm{kg} / \mathrm{min}$. The mean time to treatment was 8.3 hours (range 3.8-15.9 hours). The mean dose was $4.9 \mathrm{ng} / \mathrm{kg} / \mathrm{min}$. The patients were followed until day 30 . No significant differences were found between the groups in mortality, development of congestive heart failure, cardiogenic shock, arrhythmias, recurrent chest pain, reinfarction, peak creatine kinase concentration, or the time taken to attain peak creatine kinase concentration. No significant difference in baseline ejection fraction was noted between groups, and no significant change in ejection fraction occurred within each group or between groups. The only significant side effect was the development of facial flushing in the epoprostenol group.

In this pilot study epoprostenol was well tolerated by patients with acute myocardial infarction. No benefit from epoprostenol could be demonstrated at the dose range used when the drug was administered within 16 hours of the onset of symptoms.

Prostacyclin $\left(\mathrm{PGI}_{2}\right)$ is a potent vasodilator and inhibitor of platelet aggregation. It is a product of arachadonic acid metabolism and is synthesised by vascular endothelial cells. Its effects counteract those of thromboxane $A_{2}$, which is a vasoconstrictor and promotes platelet aggregation. It has been suggested that the balance between prostacyclin and thromboxane $A_{2}$ is an important regulator of vascular tone and the ability of platelets to aggregate. ${ }^{1}$ In theory treatment with epoprostenol sodium (prostacyclin) would be expected to have beneficial actions in acute myocardial infarction because vasospasm or platelet plugging may play a role in the pathogenesis of this condition. Evidence suggests that synthesis of prostacyclin by the blood vessel wall is reduced in patients with atherosclerosis. ${ }^{2}$ Experimental work in animals has shown that

Requests for reprints to Dr Jeffrey Kluger, Division of Cardiology, Hartford Hospital, 80 Seymour Street, Hartford CT 06115, USA.

Accepted for publication 8 July 1986 epoprostenol sodium may limit infarct size when given early in the course of myocardial infarction. ${ }^{3-5}$ The present report presents our experience with the administration of epoprostenol sodium to patients with acute myocardial infarction.

\section{Patients and methods}

PATIENTS

Between January 251983 and September 231984 patients admitted to our coronary care unit with ischaemic chest pain lasting at least 30 minutes and electrocardiographic evidence of ST segment elevation of at least $2 \mathrm{~mm}(0.2 \mathrm{mV})$ or new $Q$ waves were considered for enrolment into the study. We excluded patients in whom teatment could not be started within 16 hours of the onset of chest pain. Men (aged 18-75) or postmenopausal women (aged $<75$ years) were considered for inclusion. We excluded patients who had evidence of cardiogenic shock, unstable ventricular arrhythmias, pulmonary 
oedema, uncontrolled diabetes (blood sugar $>300$ $\mathrm{mg} / \mathrm{dl}$ ), uncontrolled hypertension (blood pressure $>200 / 120 \mathrm{~mm} \mathrm{Hg}$ ), recent previous myocardial infarction or stroke, coagulation disorder or bleeding, dialysis, recent operation, or extensive external cardiac massage, treatment with streptokinase within 10 days, and those with evidence of a malignancy.

\section{TREATMENT}

After informed consent was obtained the patients were assigned in a random double blind fashion, by means of a protocol kept by the pharmacy, to receive an infusion of epoprostenol sodium (prostacyclin, Cyclo-Prostin, Upjohn) or a corresponding infusion of placebo. The epoprostenol sodium was stored as a freeze dried powder and reconstituted with diluent buffer (sodium chloride $0.147 \% \mathrm{wt} / \mathrm{vol}$ and glycine $0 \cdot 188 \% \mathrm{wt} / \mathrm{vol}$ ). The same diluent buffer was used for placebo. These solutions were freshly prepared and changed every eight hours. Epoprostenol sodium or placebo was infused into a peripheral vein via an AccuPro volumetric infusion pump. Patients in the two treatment groups were also randomised to receive treatment within 6 hours or 6-16 hours of onset of symptoms. An initial dose of $1 \mathrm{ng} / \mathrm{kg} / \mathrm{min}$ was given and the dose was titrated to a maximum of $5 \mathrm{ng} / \mathrm{kg} / \mathrm{min}$ over one hour or until there was a $10 \%$ fall in blood pressure or a $10 \%$ rise in heart rate. The infusion was continued for 72 hours. During the final 12 hours the infusion was gradually tapered in order to avoid a rebound phenomenon. In the event of intolerable side effects, the solution was tapered over one hour until the side effect lessened or until the infusion was discontinued. In addition, patients received standard treatment with lignocaine, analgesics, and antianginal medication as directed by their attending physicians.

\section{PATIENT EVALUATION}

Samples of serum were obtained for the assay of creatine kinase, creatine kinase $\mathrm{MB}$ fraction, lactate dehydrogenase, and serum aspartate aminotransferase. Total enzyme concentrations were measured by spectrophotometry. The creatine kinase MB fraction was determined by immunoinhibition. Enzyme activities were determined at admission and at 8,16 , and 24 hours after admission. Further enzyme samples were obtained each day for the first six days of hospital admission. Standard 12 lead electrocardiograms were performed daily. Equilibrium gated pool radionuclide ventriculography was performed on day one and before discharge. Radionuclide ventriculograms were evaluated for left ventricular ejection fraction and for wall motion abnormalities.

\section{CLINICAL END POINTS}

Patients were followed throughout their hospital stay and one month after the start of the trial. Clini-

Table 1 Baseline characteristics of patients in epoprostenol sodium group and placebo group

\begin{tabular}{|c|c|c|}
\hline Characteristic & Epoprostenol $(n=23)$ & Placebo $(n=22)$ \\
\hline 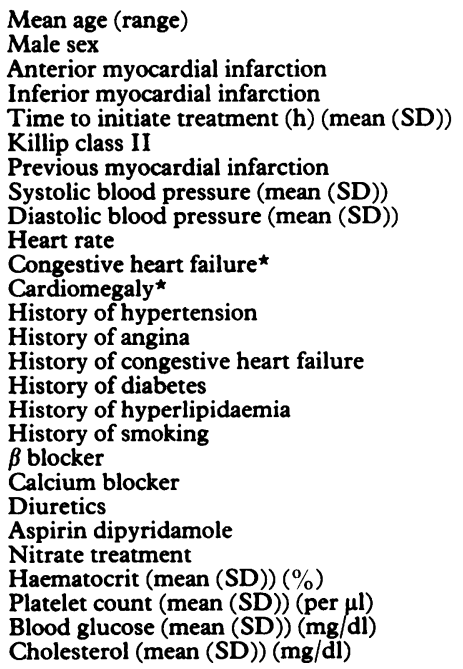 & $\begin{array}{l}56 \cdot 0(36-73) \\
16(70 \%) \\
9(39 \%) \\
14(61 \%) \\
8 \cdot 8(4 \cdot 0) \\
3(13 \%) \\
1(4 \%) \\
128(22) \\
83(12) \\
77(12) \\
5(22 \%) \\
3(13 \%) \\
5(22 \%) \\
5(22 \%) \\
1(4 \%) \\
4(17 \%) \\
4(17 \%) \\
14(61 \%) \\
4(17 \%) \\
1(4 \%) \\
4(17 \%) \\
6(26 \%) \\
1(4 \%) \\
44 \cdot 6(4 \cdot 2) \\
262(81) \times 10^{3} \\
156(54) \\
249(48)\end{array}$ & $\begin{array}{l}58 \cdot 2(43-74) \\
19(86 \%) \\
10(45 \%) \\
12(55 \%) \\
7 \cdot 8(3 \cdot 5) \\
3(14 \%) \\
3(15 \%) \\
130(23) \\
87(14) \\
74(11) \\
5(23 \%) \\
3(14 \%) \\
5(23 \%) \\
9(41 \%) \\
0 \\
1(5 \%) \\
3(14 \%) \\
13(59 \%) \\
5(23 \%) \\
1(5 \%) \\
4(18 \%) \\
7(32 \%) \\
4(18 \%) \\
44.9(4 \cdot 0) \\
281(121) \times 10^{3} \\
146(48) \\
234(42)\end{array}$ \\
\hline
\end{tabular}

$\star$ By chest $x$ ray.

$\star$ By chest $x$ ray.
Conversion: traditional units to SI units—cholesterol: $0.0259 \mathrm{mg} / \mathrm{dl}=1 \mathrm{mmol} / \mathrm{l} ;$ blood glucose: $0.556 \mathrm{mg} / \mathrm{dl}=1 \mathrm{mmol} / 1$. 
cal end points included functional status, recurrent ischaemic pain, pericarditis, development of congestive heart failure or low cardiac output, recurrent myocardial infarction, need for coronary artery bypass surgery, and death. This investigation was approved by the institutional review committee at Hartford Hospital.

\section{STATISTICAL ANALYSIS}

Results are expressed as the mean plus or minus one standard deviation. Discrete data were analysed by the $\chi^{2}$ test and by Fisher's exact test when sample sizes were small. Continuous data were analysed by an unweighted analysis of variance. Individual comparisons were then made by the unpaired $t$ test. The paired $t$ test was used to evaluate changes in factors measured before and after treatment.

\section{Results}

PATIENT CHARACTERISTICS

A total of $\mathbf{4 5}$ patients was entered into this study. Twenty three patients were randomised to receive epoprostenol sodium and 22 patients received placebo. The groups were comparable on admission (table 1).

\section{DRUG TREATMENT}

Patients in the epoprostenol sodium group received a mean maximum rate of infusion of $4.9(0.3)$ $\mathrm{ng} / \mathrm{kg} / \mathrm{min}$. The mean time to the start of treatment was $8.8(4.0)$ hours in the epoprostenol sodium group and $7.8(3.5)$ hours in the control group. Ten patients in each group had treatment started within

Table 2 Haemodynamic effects (mean (SD))

\begin{tabular}{lll}
\hline Variable & Epoprostenol & Placebo \\
\hline Systolic blood pressure: & $128(22)$ & $130(23)$ \\
$\quad$ Start of infusion & $122(19)$ & $130(19)$ \\
End of infusion & $83(12)$ & $87(14)$ \\
Diastolic blood pressure: & $77(9)$ & $87(15)$ \\
Start of infusion & $77(12)$ & $74(11)$ \\
End of infusion & $81(11)$ & $77(12)$ \\
Heart rate: & & \\
Start of infusion & & \\
End of infusion & \\
\hline
\end{tabular}

Table 3 Side effects of infusion of epoprostenol and placebo six hours of the onset of symptoms. The infusion was carried out for an average of $66(16.5)$ hours in the epoprostenol sodium group and for $63(19.8)$ hours in the placebo group. These differences were not significant. There was no significant change in blood pressure or heart rate before or after epoprostenol sodium or placebo administration (table 2).

\section{SIDE EFFECTS}

Facial flushing often developed in the epoprostenol sodium group (30\% versus $4 \%$ : $p<0.05$ ) (table 3 ). Headache and nausea were more common in the treated group than in the controls but these differences were not significant (table 3). Side effects necessitated a decrease or discontinuation of the infusion in five patients on epoprostenol sodium and in four patients on placebo.

\section{ENZYME DATA}

Analysis of serial enzyme data indicates that there was no significant difference in time to peak concentrations or in total peak creatine kinase or creatine kinase MB fraction between the placebo and epoprostenol sodium groups (table 4).

\section{EJECTION FRACTIONS}

There were no significant differences between groups for either baseline ejection fraction or changes in ejection fraction after epoprostenol sodium or placebo (table 5). Two patients died before a repeat radionuclide ventriculogram could be obtained.

\section{CLINICAL END POINTS}

Three patients died during the performance of the study. Two of these patients received placebo and the remaining patient received epoprostenol sodium. The patient who was treated with epoprostenol sodium was a 73 year old woman who was admitted with an acute inferior-apical myocardial infarction. She was given treatment within five hours of the onset of symptoms. Approximately 36 hours after the start of infusion an acute ventricu-

\begin{tabular}{|c|c|c|}
\hline & Epoprostenol $(n=23)$ & Placebo $(n=22)$ \\
\hline $\begin{array}{l}\text { Maximum rate }(\mathrm{ng} / \mathrm{kg} / \mathrm{min})(\text { mean }(\mathrm{SD})) \\
\text { Duration }(\mathrm{h})(\text { mean }(\mathrm{SD})) \\
\text { Facial flushing } \\
\text { Headache } \\
\text { Nausea } \\
\text { Blood pressure }<100 \mathrm{~mm} \mathrm{Hg} \\
\text { Heart rate }>100 \\
\text { Insufion rate changed } \\
\text { Infusion discontinued }\end{array}$ & $\begin{array}{l}4.9(0.3) \\
66 \cdot 0(16 \cdot 5) \\
7(30 \%)^{\star} \\
13(59 \%) \\
15(65 \%) \\
8(34 \%) \\
6(26 \%) \\
3(13 \%) \\
2(7 \%)\end{array}$ & $\begin{array}{c}5 \cdot 0(0 \cdot 0) \\
63 \cdot 4(19 \cdot 8) \\
1(4 \%)^{\star} \\
8(36 \%) \\
10(45 \%) \\
7(32 \%) \\
5(23 \%) \\
1(5 \%) \\
3(14 \%)\end{array}$ \\
\hline
\end{tabular}

`Fisher's exact test, $\mathrm{p}<0.05$. 
Table 4 Enzyme data (mean (SD)) in patients on epoprostenol sodium $\left(P G I_{2}\right)$ and placebo

\begin{tabular}{|c|c|c|c|c|c|c|}
\hline & $\begin{array}{l}\text { All } P G I_{2} \\
(n=23)\end{array}$ & $\begin{array}{l}\text { All placebo } \\
(n=22)\end{array}$ & $\begin{array}{l}P G I_{2}<6 h \\
(n=10)\end{array}$ & $\begin{array}{l}\text { Placebo }<6 h \\
(n=10)\end{array}$ & $\begin{array}{l}P G I_{2}>6 h \\
(n=13)\end{array}$ & $\begin{array}{l}\text { Placebo }>6 h \\
(n=12)\end{array}$ \\
\hline $\begin{array}{l}\text { CK } \\
\text { CK-MB } \\
\text { LDH } \\
\text { AST }\end{array}$ & $\begin{array}{c}1120(645) \\
122(75) \\
1054(534) \\
220(135)\end{array}$ & $\begin{array}{c}1334(800) \\
131(64) \\
1096(468) \\
223(96)\end{array}$ & $\begin{array}{c}\text { ak serum conce } \\
1341(695) \\
143(72) \\
1119(547) \\
236(129)\end{array}$ & $\begin{array}{c}\text { ons }(I U / l)^{\star} \\
1042(438) \\
113(53) \\
950(472) \\
189(64)\end{array}$ & $\begin{array}{c}951(574) \\
107(76) \\
1004(541) \\
207(143)\end{array}$ & $\begin{array}{c}1553(951) \\
144(70) \\
1218(448) \\
248(110)\end{array}$ \\
\hline $\begin{array}{l}\text { CK } \\
\text { CK-MB } \\
\text { LDH } \\
\text { AST }\end{array}$ & $\begin{array}{l}21 \cdot 7(10 \cdot 4) \\
21 \cdot 6(10 \cdot 4) \\
40 \cdot 4(15 \cdot 2) \\
25 \cdot 2(6 \cdot 4)\end{array}$ & $\begin{array}{l}\quad \text { Time to } \\
21 \cdot 9(5 \cdot 3) \\
19 \cdot 6(4 \cdot 4) \\
43 \cdot 1(18 \cdot 0) \\
27 \cdot 8(9 \cdot 4)\end{array}$ & $\begin{array}{c}\text { concentration } \\
18 \cdot 2(7 \cdot 0) \\
18 \cdot 2(7 \cdot 0) \\
38 \cdot 0(17 \cdot 2) \\
23 \cdot 4(4 \cdot 3)\end{array}$ & $\begin{array}{c}\text { 'rom onset of sym } \\
20 \cdot 4(5 \cdot 0) \\
18 \cdot 0(4 \cdot 1) \\
40 \cdot 0(21 \cdot 4) \\
25 \cdot 1(9 \cdot 5)\end{array}$ & (s) $\begin{array}{l} \\
27.4(12.0) \\
24.3(12.0) \\
42.3(14.0) \\
26.5(7.6)\end{array}$ & $\begin{array}{l}23 \cdot 1(5 \cdot 4) \\
20 \cdot 8(4 \cdot 4) \\
45 \cdot 8(14.9) \\
29 \cdot 8(7 \cdot 6)\end{array}$ \\
\hline
\end{tabular}

CK, creatine kinase; CK-MB, creatine kinase MB fraction; LDH, lactate dehydrogenase; AST, aspartate transaminase.

Table 5 Ejection fractions in patients on epoprostenol sodium $\left(P G I_{2}\right)$ and placebo

\begin{tabular}{lllllll}
\hline & $P G I_{2}($ all $)$ & Placebo (all) & $P G I_{2}<6 h$ & Placebo $<6 h$ & $P G I_{2}>6 h$ & Placebo $>6 h$ \\
\hline Initial & $0.55(0.14)$ & $0.48(0.16)$ & $0.52(0.14)$ & $0.53(0.18)$ & $0.57(0.14)$ & $0.45(0.14)$ \\
Late & $0.53(0.13)$ & $0.47(0.14)$ & $0.56(0.14)$ & $0.51(0.13)$ & $0.51(0.13)$ & $0.44(0.14)$ \\
\hline
\end{tabular}

lar septal defect developed and she subsequently died after an emergency surgical procedure. One patient in the placebo group died of an acute myocardial rupture three hours after the treatment was started. The remaining death in the placebo group was caused by electromechanical dissociation on day 2 of treatment.

Two patients required coronary artery bypass grafting. In one patient in the epoprostenol sodium group severe recurrent pain developed 34 hours after the start of treatment. She underwent emergency coronary bypass grafting. The only other patient to receive bypass grafting was treated with placebo and underwent elective bypass grafting 28 days after his myocardial infarction. Two additional patients developed recurrent pain while on the epoprostenol sodium infusion and were treated with

Table 6 Frequency of complications in patients on epoprostenol sodium and placebo

\begin{tabular}{lll}
\hline Complication & $\begin{array}{l}\text { Epoprostenol } \\
\text { sodium }(n=23)\end{array}$ & $\begin{array}{l}\text { Placebo } \\
(n=22)\end{array}$ \\
\hline Congestive heart failure & 11 & 8 \\
Reinfarction & 1 & 0 \\
Cardiogenic shock & 0 & 2 \\
Death within 30 days & 1 & 2 \\
Cardiac surgery & 2 & 2 \\
Intra-aortic balloon pump & $4{ }^{\star}$ & 6 \\
Pericarditis & 5 & 1 \\
Ventricular fibrillation & 0 & 1 \\
Ventricular tachycardia & 2 & 0 \\
Atrial fibrillation & 2 & 2 \\
Cardiac arrest & 1 & 17 \\
Recurrent chest pain & 17 & $1 \cdot 6(2 \cdot 0)$ \\
No of pain episodes per patient & $2 \cdot 6(3 \cdot 3)$ & $5 \cdot 2(7 \cdot 8)$ \\
$\quad$ (mean (SD)) & $8 \cdot 6(12 \cdot 0)$ & \\
Morphine sulphate required (mg) & \\
$\quad$ (mean (SD)) & & \\
\hline p = 0·11. & &
\end{tabular}

intra-aortic balloon pumps. One patient who received epoprostenol sodium had confirmed evidence of reinfarction three days after the completion of the epoprostenol sodium infusion.

Seventeen patients in each group had episodes of recurrent chest pain during hospital stay. There was no statistically significant difference between the morphine requirements of the two groups or the number of chest pain episodes, although the epoprostenol groups had slightly more. There was no significant difference in the number of chest pain episodes that occurred during the infusion and after the infusion was stopped. The number of patients reporting episodes of angina at the end of the 30 day follow up was similar in each group.

\section{Discussion}

In this study we compared the effects of the administration of an infusion of epoprostenol sodium with those of placebo in patients with acute myocardial infarction. We did not find that the drug had any significant effect upon the clinical end points examined, on myocardial infarct size as judged by an increase in serum enzyme activities, or on mortality rates.

\section{RATIONALE FOR EPOPROSTENOL SODIUM IN} ACUTE MYOCARDIAL INFARCTION

Epoprostenol sodium infusions at dosages comparable to those used in this study have been shown to reduce platelet aggregation. ${ }^{6}$ It has also been reported to disaggregate platelets. ${ }^{17}$ Epoprostenol limited the extent of myocardial necrosis in experi- 
mental acute myocardial infarction. ${ }^{5}$ Its ability to prevent platelet aggregation may also be a potential mechanism for a beneficial effect in acute myocardial ischaemia. In a necropsy study of patients who died of acute myocardial infarction platelet microemboli were often found occluding small myocardial vessels in the area of distribution of the infarct artery. ${ }^{8}$

Uchida et al reported that the intracoronary infusion of epoprostenol sodium was associated with the recanalisation of an obstructed coronary artery in three of four patients with acute myocardial infarction. ${ }^{9}$ Henriksson et al have recently reported the results of a study similar to our own. ${ }^{10}$ They found that the activity of creatine kinase $M B$ was significantly lower in those patients who received treatment with epoprostenol sodium within six hours of the onset of symptoms than in patients on placebo. There were, however, a disproportionate number of patients with anterior wall myocardial infarctions in the control group. Henriksson et al reported two examples of infarct extension after the infusion was stopped in the group on epoprostenol soidum. Although this finding did not reach statistical significance, in an earlier preliminary report they suggested that the myocardium at risk might be spared from infarction by the administration of epoprostenol sodium and that the infarction is delayed until after the infusion is stopped. ${ }^{11} \mathrm{We}$ did not confirm this suggestion of a beneficial effect of epoprostenol sodium in myocardial infarction. Nor did we see a higher frequency of recurrent myocardial infarctions or recurrent chest pain in our treated group. Thus we found no evidence that epoprostenol sodium delayed the completion of the myocardial infarction until after the infusion.

Because one of the study objectives was to evaluate the safety of the administration of the drug in patients with acute myocardial infarction the number of patients was limited. This small series makes it difficult to detect the effects of a given intervention that may be only moderate. In addition, the average (SD) time to the start of treatment in the group on epoprostenol sodium was $8.8(4 \cdot 0)$ hours. Thus the drug may have been administered too late to produce any benefit. In previous experimental work in animal models a much higher dose of epoprostenol sodium was used. ${ }^{5}$ It might be necessary to use higher dosages of epoprostenol sodium in order to obtain beneficial effects on myocardial infarction. Also the risk of complications in the study population was low because they were in Killip class I and II. This study does not exclude the possibility that other individuals who may be at higher risk could benefit from the administration of epoprostenol sodium.
CLINICAL IMPLICATIONS

While epoprostenol sodium can be given safely to patients with acute myocardial infarction in a dose up to $5 \mathrm{ng} / \mathrm{kg} / \mathrm{min}$, we were unable to show any significant benefit in the clinical end points examined, myocardial infarct size, or mortality. This issue may be resolved by larger trials especially those in which the agent is administered earlier in the course of acute myocardial infarction and possibly in higher dosage.

This study was fully supported by the Upjohn Company, Kalamazoo, Michigan.

\section{References}

1 Korbut R, Morcada S. Prostacyclin and thromboxane $A_{2}$ interaction in vivo. Regulation by aspirin and relationship with anti-thrombotic therapy. Thromb Res 1978;13:489-500.

2 Neri Serneri GG, Masotti G, Pogges L, Galanti G, Morettini A, Scarti L. Reduced prostacyclin production in patients with different manifestations of ischemic heart disease. Am $f$ Cardiol 1982;49: 1146-51.

3 Jugdutt BI, Hutchins GM, Bulkley BH, Becker L. Dissimilar effects of prostacyclin, prostaglandin $E_{1}$, and prostaglandin $E_{2}$ in myocardial infarct size after coronary occlusion in conscious dogs. Circ Res 1982;49:685-700.

4 Ribeiro LGT, Brandon TA, Hopkins DG, Reduto LA, Taylor AA, Miller RR. Prostacyclin in experimental myocardial ischemia: effects on hemodynamics, regional myocardial blood flow, infarct size and mortality. Am f Cardiol 1981;47:835-40.

5 Melin JA, Becker LC. Salvage of ischemic myocardium by prostacyclin during experimental myocardial infarction. $\mathcal{F}$ Am Coll Cardiol 1983;2:279-86.

6 O'Grady J, Bunting S, Flower R, Fowle ASE, Higgs EA, Moncada S. Effects of intravenous infusion of prostacyclin $\left(\mathrm{PGI}_{2}\right)$ in man. Prostaglandins 1980;19: 319-32.

7 Bayer B, Blass K, Forster W. Antiaggregatory effect of prostacyclin $\left(\mathrm{PGI}_{2}\right)$ in vivo. $\mathrm{Br} \mathcal{f}$ Pharmacol 1979;66:10-2.

8 Falk E. Unstable angina with fatal outcome: dynamic coronary thrombosis leading to infarction and/or sudden death. Circulation 1985;71:699-708.

9 Uchida Y, Hanai T, Hasegawa K, Kawamura K, Oshima $T$. Recanalization of obstructed coronary artery by intracoronary administration of prostacyclin in patients with acute myocardial infarction. Adv Prostaglandin Thromboxane Leukotriene Res 1983;11:377-83.

10 Henriksson P, Edhag O, Wennmalm Å. Prostacyclin infusion in patients with acute myocardial infarction. Br Heart f 1985;53:173-9.

11 Edhag O, Henriksson P, Wennmalm A. Prostacyclin infusion in patients with acute myocardial infarction (preliminary report). [Letter]. $N$ Engl $\mathcal{f}$ Med 1983;308:1032-3. 